\title{
Living-donor lobar lung transplantation
}

\section{Daisuke Nakajima, Hiroshi Date}

Department of Thoracic Surgery, Kyoto University Graduate School of Medicine, Kyoto, Japan

Contributions: (I) Conception and design: Both authors; (II) Administrative support: None; (III) Provision of study materials or patients: Both authors; (IV) Collection and assembly of data: Both authors; (V) Data analysis and interpretation: Both authors; (VI) Manuscript writing: Both authors; (VII) Final approval of manuscript: Both authors.

Correspondence to: Hiroshi Date. Department of Thoracic Surgery, Kyoto University Graduate School of Medicine, 54 Shogoin-kawahara-cho, Sakyoku, Kyoto 606-8507, Japan. Email: hdate@kuhp.kyoto-u.ac.jp.

\begin{abstract}
Living-donor lobar lung transplantation (LDLLT) has become an important life-saving option for patients with severe respiratory disorders, since it was developed by a group in the University of Southern California in 1993 and introduced in Japan in 1998 in order to address the current severe shortage of brain-dead donor organs. Although LDLLT candidates were basically limited to critically ill patients who would require hospitalization, the long-term use of steroids, and/or mechanical respiratory support prior to transplantation, LDLLT provided good post-transplant outcomes, comparable to braindead donor lung transplantation in the early and late phases. In Kyoto University, the 5- and 10-year survival rates after LDLLT were reported to be $79.0 \%$ and $64.6 \%$, respectively. LDLLT should be performed under appropriate circumstances, considering the inherent risk to the living donor. In our transplant program, all living donors returned to their previous social lives without any major complications, and living-donor surgery was associated with a morbidity rate of $<15 \%$. Both functional and anatomical size matching were preoperatively performed between the living-donor lobar grafts and recipients. Precise size matching before surgery could provide a favorable pulmonary function and exercise capacity after LDLLT. Various transplant procedures have recently been developed in LDLLT in order to deal with the issue of graft size mismatching in recipients, and favorable post-transplant outcomes have been observed. Native upper lobesparing and/or right-to-left inverted transplantation have been performed for undersized grafts, while singlelobe transplantation has been employed with or without contralateral pneumonectomy and/or delayed chest closure for oversized grafts.
\end{abstract}

Keywords: Living donor; lobar lung transplantation; size matching; brain-dead donor; cadaveric lung transplantation

Submitted Mar 12, 2020. Accepted for publication Jan 27, 2021.

doi: $10.21037 /$ jtd-2021-07

View this article at: http://dx.doi.org/10.21037/jtd-2021-07

\section{Introduction}

The Japanese organ transplant law was amended in July 2010 so that families could consent to organ donation, which gradually increased the number of organ donations from brain-dead donors. However, the number of lung transplant candidates newly registered in the Japan Organ Transplantation Network has nearly doubled, which has resulted in a severe donor organ shortage (Figure 1). Thus, the average wait time for brain-dead donor lungs still exceeds 800 days in Japan, indicating that many patients on the waiting list die without the opportunity to receive lung transplantation (1).

Living-donor lobar lung transplantation (LDLLT) was developed by a group in the University of Southern California in 1993 and was introduced in Japan in 1998 in order to resolve a serious donor organ shortage $(2,3)$. By the end of 2019, a total of 760 lung transplant procedures had been performed in Japan, and LDLLT accounted for 30.8\% of these procedures, suggesting that LDLLT has become 


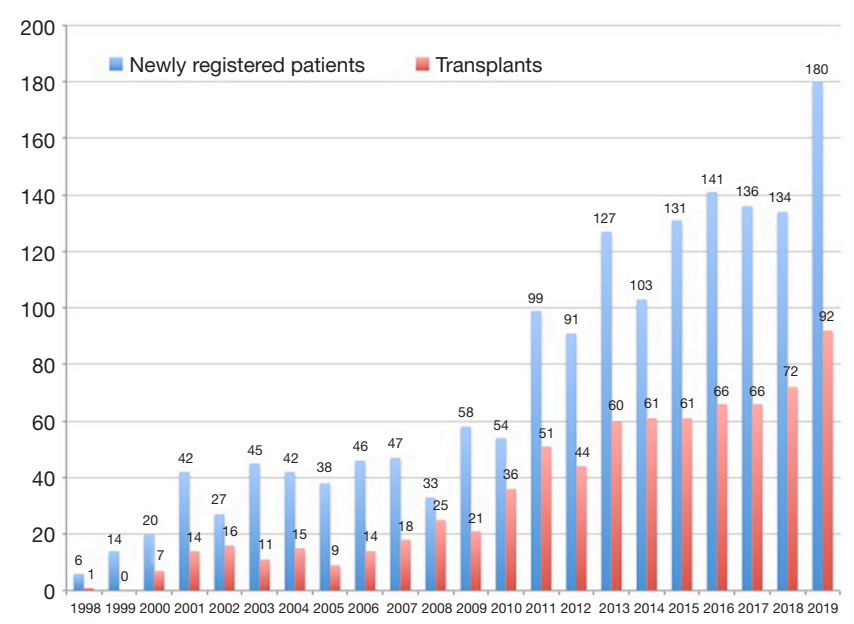

Figure 1 The numbers of lung transplantation performed in Japan and newly registered patients in the Japan Organ Transplantation Network have been increasing since the Japanese organ transplant law was revised in July 2010.

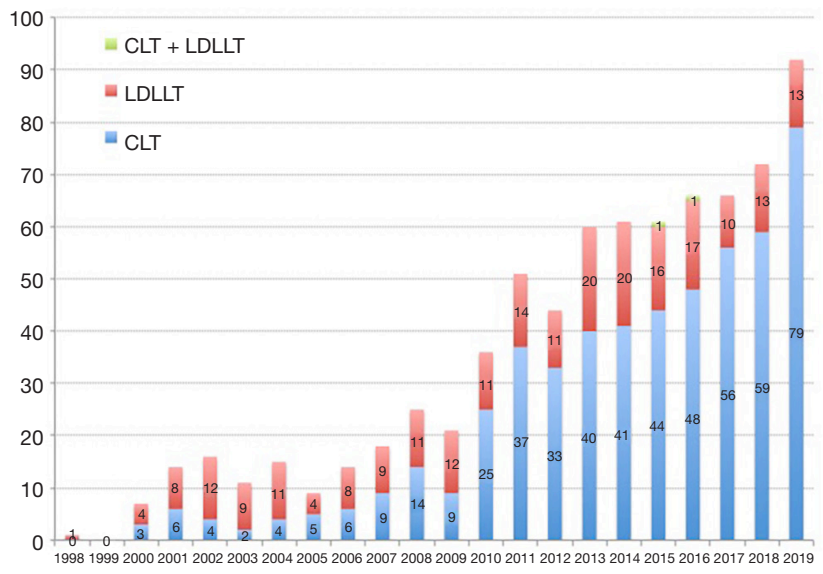

Figure 2 By the end of 2019, lung transplantation had been performed in 760 patients and LDLLT had been performed in 234 patients (30.8\%). CLT, cadaveric lung transplantation; LDLLT, living-donor lung transplantation.

an important life-saving option for patients with severe respiratory disorders in Japan (Figure 2).

In standard LDLLT, the right and left lower lobes are retrieved from two healthy donors and are implanted in a single recipient. There are some advantages and disadvantages of LDLLT in comparison to cadaveric lung transplantation (CLT), as shown in Table 1 (4). Given that lobectomy through posterolateral thoracotomy is required for healthy living donors, LDLLT candidates are basically limited to critically ill patients who are not expected to survive the long waiting period for brain-dead donor lungs. Furthermore, LDLLT can only be justified when it can provide acceptable post-transplant outcomes equivalent to CLT (5). There are also concerns about graft size mismatch due to the use of small lobar grafts for LDLLT patients. This chapter will update the post-transplant outcomes of patients who underwent LDLLT under critical and serious conditions and focus on enhanced lobar lung transplant techniques and strategies using native upper lobe-sparing, right-to-left inverted, and single-lobe transplantation.

\section{Inclusion criteria for LDLLT recipient}

In Kyoto University, LDLLT candidates should be less 
Table 1 Advantages and disadvantages of living-donor lobar lung transplantation

\begin{tabular}{l}
\hline Advantages \\
Short waiting time \\
Short ischemic time \\
Perfect graft with less injury and infection \\
Scheduled operation \\
Similar HLA \\
Disadvantages \\
Lobectomy in healthy donor(s) \\
Difficult size matching \\
Three operating rooms for three teams (recipient and two \\
donors)
\end{tabular}

HLA, human leukocyte antigen.

than 65 years of age and meet the criteria for conventional CLT (4). Importantly, LDLLT is only indicated for critically ill patients and/or pediatric patients who are unlikely to survive the long waiting time for brain-dead donor lungs. In our experience, pediatric recipients (age $<15$ years) accounted for $24 \%$ of the patients who underwent LDLLT. Approximately $60 \%$ of the LDLLT patients were significantly underweight [body mass index $(\mathrm{BMI})<18.5$ ], were hospitalized at the time of transplantation, and required the long-term steroid use prior to transplantation. Recipient illness of increased severity, including progressive or severe malnutrition, hospitalization at the time of transplantation, and the longterm use of steroids before surgery, have been listed as risk factors for post-transplant mortality according to a report from the registry of the International Society for Heart and Lung Transplantation (ISHLT) (6,7). Moreover, $10 \%$ of the LDLLT patients required mechanical respiratory support when they underwent transplantation. Among them, half of the patients were intubated after LDLLT was scheduled, and thus the preoperative period for which they were on mechanical ventilation was significantly short, ranging from 4 to 41 days, which suggested that the patients might have good potential for rehabilitation after transplantation. Moreover, all intubated LDLLT candidates were young, ranging in age from 6 to 24 years. In a consensus document for the selection of lung transplant candidates from the ISHLT, although mechanical ventilation and/ or extracorporeal life support have basically been listed
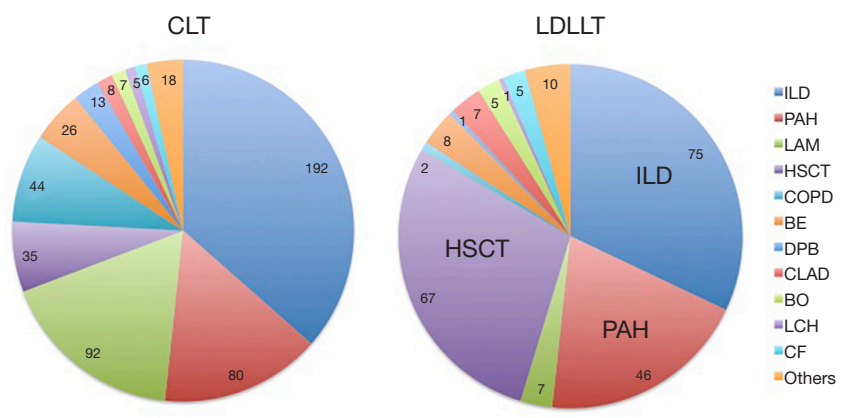

Figure 3 Indications for CLT and LDLLT. CLT, cadaveric lung transplantation; LDLLT, living-donor lung transplantation; ILD, interstitial lung disease; PAH, pulmonary arterial hypertension; LAM, lymphangioleiomyomatosis; HSCT, hematopoietic stem cell transplantation; COPD, chronic obstructive pulmonary disease; BE, bronchiectasis; DPB, diffuse panbronchiolitis; CLAD, chronic lung allograft dysfunction; $\mathrm{BO}$, bronchiolitis obliterans; LCH, Langerhans cell histiocytosis; CF, cystic fibrosis.

as relative contraindications for lung transplantation, mechanical support has been recommended for young patients with good rehabilitation potential $(8,9)$.

The primary indications for brain-dead donor and livingdonor lung transplantation in Japan are presented in Figure 3. LDLLT was indicated for various types of lung diseases, including restrictive, obstructive, infectious, and vascular lung diseases (3). Of these, three major indications included interstitial lung disease (32.1\%), pulmonary complications after hematopoietic stem cell transplantation (HSCT) (28.6\%), and pulmonary arterial hypertension (19.7\%). According to the data collected from 6 transplant centers in Japan, patients with pulmonary complications after HSCT were generally considered high-risk candidates for lung transplantation, because the median BMI of the patients was 15.0 (range, 10.2-24.3), 21\% of the patents required mechanical respiratory support, and $84 \%$ of the patients suffered from hypercapnia with a median $\mathrm{CO}_{2}$ level of 61.0 Torr at the time of transplantation (10).

\section{Operative characteristics of LDLLT}

Lobar graft(s) are implanted as a whole lung in LDLLT, and thus cardiopulmonary support is definitely required during the transplant procedure. Extracorporeal membrane oxygenation (ECMO) is basically utilized for cardiopulmonary support, whereas conventional 


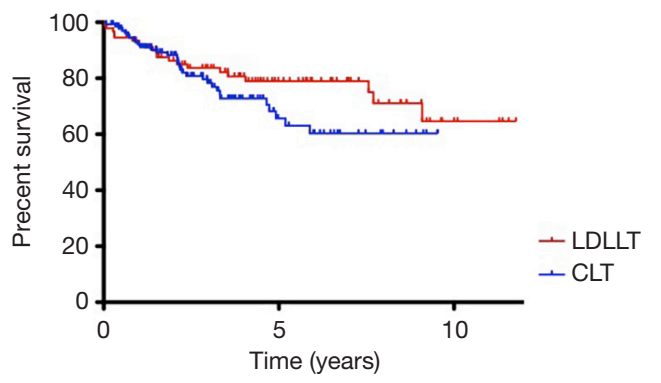

Figure 4 The 5- and 10-year survival rates after LDLLT and CLT in Kyoto University. LDLLT, living-donor lobar lung transplantation; CLT, cadaveric lung transplantation.

cardiopulmonary bypass is employed for pediatric patients and/or transplant cases that require concurrent cardiac repair, such as closure of atrial septal defect (11-13).

A standard LDLLT procedure requires three surgical teams and a back-table team (Table 1). We communicate each other closely to identify the appropriate timing of retrieval of the living-donor lobar graft to minimize the graft ischemic time, and thus, according to our data, the median total ischemic time of the living-donor graft was 150 minutes (range, 80-301 minutes), which was significantly shorter in comparison to procedures performed using brain dead-donor grafts (median: 459 minutes; range, 242-742 minutes) (5).

\section{The post-LDLLT outcomes}

Living-donor lobar grafts are less injured than brain-dead donor lungs that are frequently subjected to intensive care unit (ICU)-related complications and injuries acquired during brain death (14). Furthermore, the graft ischemic time in LDLLT is significantly shorter in comparison to CLT, as described before. Thus, the living-donor lobar graft is "small but perfect", which possibly results in significantly better pulmonary oxygenation after transplantation $(5,15)$.

According to our data, ECMO support was required after surgery by $11 \%$ of the patients, the 30 -day mortality rate was $2 \%$, and the in-hospital mortality rate was $7 \%$; these outcomes were equivalent to the post-CLT outcomes (5). The causes of in-hospital death in the acute phase included primary graft dysfunction (PGD), disseminated intravascular coagulation (DIC), aspiration pneumonitis, and sepsis.

Most LDLLT patients developed unilateral chronic lung allograft dysfunction (CLAD), which suggests that implanting two lobes obtained from different donors is of great benefit to the patient because the contralateral unaffected lung graft may function as a reservoir when CLAD occurs unilaterally (16). In our experience, the incidence of CLAD per donor in the LDLLT patients (14\%) was actually slightly lower than that in CLT patients (22\%).

According to our data in Kyoto University, we had 92 LDLLT and 135 CLT between 2008 and 2019. The 5- and 10-year survival rates were $79.0 \%$ and $64.6 \%$ after LDLLT and $65.7 \%$ and $60.3 \%$ after CLT, respectively (Figure 4 ). The causes of late death included CLAD, infection, and malignancy (breast cancer, bladder cancer, gastric cancer, and post-transplant lymphoproliferative disorders), in descending order.

\section{Living-donor selection and outcome}

The eligibility criteria for living donation in Kyoto University are summarized as follows: (I) the age of the living donor should be between 20 and 60 years of age; (II) the $\mathrm{ABO}$ blood type should be compatible with recipient; (III) donor candidates should be relatives within the third degree or a spouse; (VI) arterial oxygen tension should be $\geq 80$ Torr on room air; and (V) forced vital capacity (FVC) and forced expiratory volume in one second (FEV1) should be $\geq 85 \%$ of the predicted values (4).

It is no exaggeration to say that the donor postoperative outcome is one of the most important things in LDLLT. We performed lobectomy in 151 live donors for 69 bilateral and 13 single lung transplantation between June 2008 and May 2018. Post-operative complications were observed in 22 donors $(14.6 \%)$, including pneumothorax $(\mathrm{n}=8)$, pleural effusion $(n=7)$, pleuritis $(n=3)$, chylothorax $(n=2)$, hemothorax $(n=1)$, and empyema $(n=1)$. Importantly, all donors survived and returned to their previous lifestyle $(17,18)$.

\section{Size matching between the living-donor lobar graft and recipient}

In LDLLT, only lobe(s) are implanted in a recipient as a whole lung, and thus size matching between the donor lobe and the recipient is sometimes difficult. The use of oversized grafts could increase airway resistance with atelectasis and also elevate pulmonary vascular resistance with hemodynamic instability, especially at the time of chest closure. Conversely, the use of grafts that are too small 


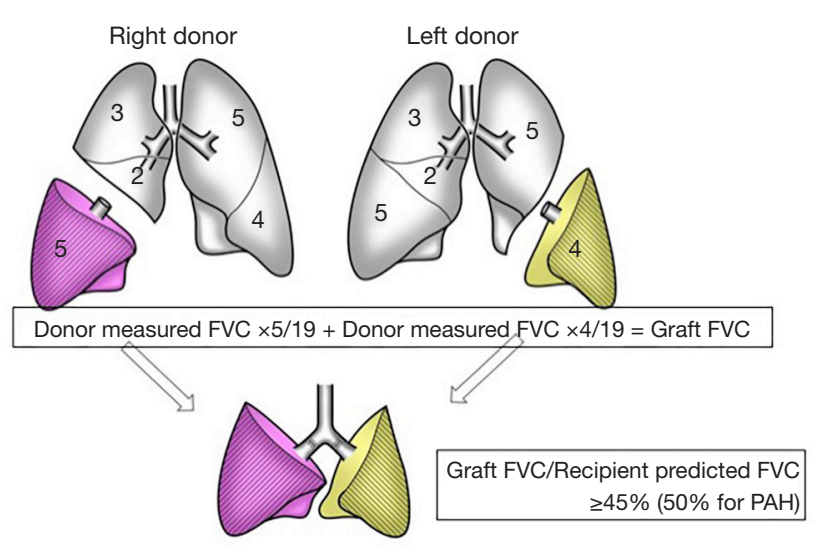

Figure 5 Date's formula for functional size matching between a living-donor lobar graft and a recipient. FVC, forced vital capacity; PAH, pulmonary arterial hypertension.

could increase pulmonary arterial pressure and easily result in pulmonary edema after implantation.

The pulmonary function can be directly assessed in living donors but not in brain-dead donors, which enables us to perform more precise functional size matching in LDLLT. For functional size matching, we estimate the graft forced vital capacity (FVC) based on the measured donor FVC and the number of resected pulmonary segments, using Date's previously reported formula (3). A calculated graft FVC of $>45 \%$ or $50 \%$ (for pulmonary arterial hypertension) of the recipient predicted FVC is considered to indicate acceptable size matching of the graft to the LDLLT recipient (Figure 5). We previously reported that if graft size matching is performed precisely, LDLLT can provide a good long-term pulmonary function and exercise capacity similar to CLT. The post-transplant lung function of LDLLT and CLT patients showed a steady improvement over the first 2 years after transplantation and reached approximately $70 \%$ of the recipient predicted value (19).

For anatomical size matching, 3-dimensional computed tomography (3D-CT) volumetry is performed for both the donor and recipient, as reported previously (20). The $3 \mathrm{D}$ CT volumetry is especially useful when we evaluate the oversized graft volume. Based on our experience, the upper limit of the ratio of the graft volume to the recipient's chest cavity volume appears to be $200 \%$.

\section{New strategies for size mismatch}

Only two lower lobes may be too small for big male adults. We have developed two transplant procedures for undersized graft; native upper lobe-sparing transplantation and right-to-left inverted transplantation (21-27). When an adult lower lobe may be too big for a small child, we employ a downsizing technique and single-lobe transplantation for oversized graft (11-13,28-30).

\section{Native upper lobe-sparing transplantation}

The indication for using the native upper lobe-sparing technique is as follows: the native upper lobes are less injured on high-resolution CT and are better perfused on perfusion scintigraphy in comparison to other lobes. Importantly, the native lungs should not be infected and the interlobar fissure should be well developed $(21,24,26,27)$. The surgical procedure is similar to standard LDLLT, except that the graft bronchus is anastomosed distally to the second carina, the graft pulmonary artery is anastomosed to the interlobar artery, and the graft pulmonary vein is anastomosed to the lower pulmonary vein.

The spared upper lobes can reduce intrathoracic dead space after implantation and can provide an adequate chest cavity for the graft so that the small lobar graft can work more efficiently. Actually we previously reported that before surgery, the mean graft FVC/recipient predicted FVC (FVC size matching) was $45.2 \%$, whereas it significantly increased to $76.9 \%$ and $69.4 \%$ at 1 year and 2 years after sparing transplantation, respectively (27).

\section{Right-to-left inverted transplantation}

The indication for right-to-left inverted transplantation is a 
graft FVC of $<60 \%$ of the recipient predicted FVC or that the left lower lobectomy would be technically difficult in the donor due to the anatomy of the interlobar pulmonary artery $(22,23)$. The right lower lobe and left lower lobe consist of 5 segments and 4 segments, respectively, which theoretically indicates that the right lower lobe volume is $25 \%$ larger than the left lower lobe volume. Therefore, if we implant the larger right lower lobe instead of the left lower lobe into the recipient left chest cavity, we can resolve a size mismatch issue. We previously reported that the mean preoperative FVC size matching was significantly increased from $52.4 \%$ in a non-inverted setting to $57.6 \%$ in an inverted setting (22).

The donor right lower lobe is inverted and implanted into the recipient left chest cavity, and thus the surgical procedure is more complicated in comparison to the standard LDLLT technique. First, the graft bronchus is anastomosed to the recipient left upper lobe bronchus, leaving the recipient left lower bronchial stump closed. Therefore, the recipient left bronchus is carefully dissected and the bronchial stump is reinforced with the pericardial fat pad in order to prevent the postoperative bronchopleural fistula $(23,31)$. Then pulmonary artery anastomosis is performed without twisting behind the bronchus. Finally, the graft pulmonary vein is anastomosed to the recipient left upper pulmonary vein or left appendage. As of 2019, we had experienced 15 inverted transplant cases and no complications were observed in bronchial or vascular anastomoses in the early and late phases after transplantation (22).

\section{Single-lobe transplantation}

Functional and anatomical size matching between the oversized graft and a small patient is very important for single-lobe transplantation. We previously reported that patients who received grafts with an FVC of $<60 \%$ and a CT volume of $>170 \%$ developed severe primary graft dysfunction after single-lobe transplantation (29). Furthermore, when the graft volume is $<200 \%$ of the recipient chest cavity volume, the graft can be finally fitted into the small chest cavity of the recipient with or without contralateral pneumonectomy and/or delayed chest closure.

Single-lobe transplantation has been employed for various types of lung disease that mainly affect children (29). Single-lobe LDLLT was successfully performed even for patients with severe pulmonary arterial hypertension
$(11,12,30)$. Although single-lobe transplantation has provided acceptable post-transplant outcomes, bilateral LDLLT seems to be a better option.

\section{Acknowledgments}

Funding: None.

\section{Footnote}

Provenance and Peer Review: This article was commissioned by the Guest Editor (Jonathan D'Cunha) for the series "Lung Transplantation: Past, Present, and Future" published in Fournal of Thoracic Disease. The article has undergone external peer review.

Conflicts of Interest: Both authors have completed the ICMJE uniform disclosure form (available at http:// dx.doi.org/10.21037/jtd-2021-07). The series "Lung Transplantation: Past, Present, and Future" was commissioned by the editorial office without any funding or sponsorship. Both authors have no other conflicts of interest to declare.

Ethical Statement: Both authors are accountable for all aspects of the work in ensuring that questions related to the accuracy or integrity of any part of the work are appropriately investigated and resolved.

Open Access Statement: This is an Open Access article distributed in accordance with the Creative Commons Attribution-NonCommercial-NoDerivs 4.0 International License (CC BY-NC-ND 4.0), which permits the noncommercial replication and distribution of the article with the strict proviso that no changes or edits are made and the original work is properly cited (including links to both the formal publication through the relevant DOI and the license). See: https://creativecommons.org/licenses/by-nc-nd/4.0/.

\section{References}

1. Sato M, Okada Y, Oto T, et al. Registry of the Japanese Society of Lung and Heart-Lung Transplantation: official Japanese lung transplantation report, 2014. Gen Thorac Cardiovasc Surg 2014;62:594-601.

2. Starnes VA, Woo MS, MacLaughlin EF, et al. Comparison of outcomes between living donor and cadaveric lung transplantation in children. Ann Thorac Surg 
1999;68:2279-83; discussion 2283-4.

3. Date H, Aoe M, Nagahiro I, et al. Living-donor lobar lung transplantation for various lung diseases. J Thorac Cardiovasc Surg 2003;126:476-81.

4. Date H. Living-related lung transplantation. J Thorac Dis 2017;9:3362-3371.

5. Date H, Sato M, Aoyama A, et al. Living-donor lobar lung transplantation provides similar survival to cadaveric lung transplantation even for very ill patients. Eur J Cardiothorac Surg 2015;47:967-72.

6. Allen JG, Arnaoutakis GJ, Weiss ES, et al. The impact of recipient body mass index on survival after lung transplantation. J Heart Lung Transplant 2010;29:1026-33.

7. Yusen RD, Edwards LB, Dipchand AI, et al. The Registry of the International Society for Heart and Lung Transplantation: Thirty-third Adult Lung and HeartLung Transplant Report-2016; Focus Theme: Primary Diagnostic Indications for Transplant. J Heart Lung Transplant 2016;35:1170-84.

8. Weill D, Benden C, Corris PA, et al. A consensus document for the selection of lung transplant candidates: 2014-An update from the Pulmonary Transplantation Council of the International Society for Heart and Lung Transplantation. J Heart Lung Transplant 2015;34:1-15.

9. Toyooka S, Yamane M, Oto T, et al. Favorable outcomes after living-donor lobar lung transplantation in ventilatordependent patients. Surg Today 2008;38:1078-82.

10. Chen-Yoshikawa TF, Sugimoto S, Shiraishi T, et al. Prognostic Factors in Lung Transplantation After Hematopoietic Stem Cell Transplantation. Transplantation 2018;102:154-61.

11. Date H, Sano Y, Aoe M, et al. Living-donor single-lobe lung transplantation for primary pulmonary hypertension in a child. J Thorac Cardiovasc Surg 2002;123:1211-3.

12. Takahashi K, Chen F, Ikeda T, et al. Single-Lobe Lung Transplantation for Rapidly Deteriorating Pulmonary Venoocclusive Disease. Ann Thorac Surg 2013;95:689-91.

13. Sonobe M, Bando T, Kusuki S, et al. Living-donor, singlelobe lung transplantation and simultaneous contralateral pneumonectomy in a child. J Heart Lung Transplant 2011;30:471-4.

14. Meers C, Van Raemdonck D, Verleden GM, et al. The number of lung transplants can be safely doubled using extended criteria donors; a single-center review. Transpl Int 2010;23:628-35.

15. Mizota T, Miyao M, Yamada T, et al. Graft dysfunction immediately after reperfusion predicts short-term outcomes in living-donor lobar lung transplantation but not in cadaveric lung transplantation. Interact Cardiovasc Thorac Surg 2016;22:314-20.

16. Miyamoto E, Chen F, Aoyama A, et al. Unilateral chronic lung allograft dysfunction is a characteristic of bilateral living-donor lobar lung transplantation†. Eur J Cardiothorac Surg 2015;48:463-9.

17. Chen F, Yamada T, Sato M, et al. Postoperative pulmonary function and complications in living-donor lobectomy. J Heart Lung Transplant 2015;34:1089-94.

18. Toyazaki T, Chen F, Shoji T, et al. Postoperative pleural effusion in living lobar lung transplant donors. Gen Thorac Cardiovasc Surg 2011;59:440-2.

19. Nakajima D, Chen-Yoshikawa TF, Ohsumi A, et al. Living-donor lobar lung transplants provide comparable pulmonary function to cadaveric lung transplants. J Thorac Cardiovasc Surg 2019;159:e87-90.

20. Chen-Yoshikawa TF, Date H. Three-dimensional image in lung transplantation. Gen Thorac Cardiovasc Surg 2018;66:19-26.

21. Aoyama A, Chen F, Minakata K, et al. Sparing Native Upper Lobes in Living-Donor Lobar Lung Transplantation: Five Cases From a Single Center. Am J Transplant 2015;15:3202-7.

22. Chen-Yoshikawa TF, Tanaka S, Yamada Y, et al. Intermediate outcomes of right-to-left inverted livingdonor lobar lung transplantation. Eur J Cardiothorac Surg 2019;56:1046-53.

23. Chen F, Miyamoto E, Takemoto M, et al. Right and Left Inverted Lobar Lung Transplantation. Am J Transplant 2015;15:1716-21.

24. Date H, Aoyama A, Hijiya K, et al. Outcomes of various transplant procedures (single, sparing, inverted) in livingdonor lobar lung transplantation. J Thorac Cardiovasc Surg 2017;153:479-86.

25. Fujinaga T, Bando T, Nakajima D, et al. Living-donor lobar lung transplantation with sparing of bilateral native upper lobes: A novel strategy. J Heart Lung Transplant 2011;30:351-3.

26. Goda Y, Motoyama H, Aoyama A, et al. Right-to-left inverted living-donor lobar lung transplantation combined with sparing of native right upper lobe. J Heart Lung Transplant 2017;36:483-5.

27. Takahagi A, Chen-Yoshikawa TF, Saito M, et al. Native upper lobe-sparing living-donor lobar lung transplantation maximizes respiratory function of the donor graft. J Heart Lung Transplant 2019;38:66-72.

28. Chen F, Fujinaga T, Shoji T, et al. Perioperative assessment of oversized lobar graft downsizing in living-donor lobar 
lung transplantation using three-dimensional computed tomographic volumetry. Transpl Int 2010;23:e41-4.

29. Date H, Shiraishi T, Sugimoto S, et al. Outcome of livingdonor lobar lung transplantation using a single donor. J Thorac Cardiovasc Surg 2012;144:710-5.

30. Toyooka S, Sano Y, Yamane M, et al. Long-term follow-up of living-donor single lobe transplantation for idiopathic pulmonary arterial hypertension in a child. J Thorac Cardiovasc Surg 2008;135:451-2.

31. Kayawake H, Chen-Yoshikawa TF, Aoyama A, et al. Surgical management of bronchial stumps in lobar lung transplantation. J Thorac Cardiovasc Surg 2018;156:451-60.
Cite this article as: Nakajima D, Date H. Living-donor lobar lung transplantation. J Thorac Dis 2021;13(11):6594-6601. doi: $10.21037 /$ jtd-2021-07 